\title{
Cluster analysis of fasciolosis in dairy cow herds in Munster province of Ireland and detection of major climatic and environmental predictors of the exposure risk
}

\author{
Nikolaos Selemetas', Paul Phelan², Padraig O'Kiely², Theo de Waal ${ }^{1}$ \\ ${ }^{1}$ UCD School of Veterinary Medicine, University College Dublin, Dublin, Ireland; ${ }^{2}$ Teagasc, Animal and \\ Grassland Research and Innovation Centre, Grange, Dunsany Co, Meath, Ireland
}

\begin{abstract}
Fasciolosis caused by Fasciola hepatica is a widespread parasitic disease in cattle farms. The aim of this study was to detect clusters of fasciolosis in dairy cow herds in Munster Province, Ireland and to identify significant climatic and environmental predictors of the exposure risk. In total, 1,292 dairy herds across Munster was sampled in September 2012 providing a single bulk tank milk (BTM) sample. The analysis of samples by an in-house antibody-detection enzyme-linked immunosorbent assay (ELISA), showed that $65 \%$ of the dairy herds $(\mathrm{n}=842)$ had been exposed to F. hepatica. Using the Getis-Ord Gi* statistic, 16 high-risk and 24 low-risk $(\mathrm{P}<0.01)$ clusters of fasciolosis were identified. The spatial distribution of high-risk clusters was more dispersed and mainly located in the northern and western regions of Munster compared to the low-risk clusters that were mostly concentrated in the southern and eastern regions. The most significant classes of variables that could reflect the difference between high-risk and low-risk clusters were the total number of wet-days and rain-days, rainfall, the normalized difference vegetation index (NDVI), temperature and soil type. There was a bigger proportion of well-drained soils among the low-risk clusters, whereas poorly drained soils were more common among the high-risk clusters. These results stress the role of precipitation, grazing, temperature and drainage on the life cycle of F. hepatica in the temperate Irish climate. The findings of this study highlight the importance of cluster analysis for identifying significant differences in climatic and environmental variables between high-risk and low-risk clusters of fasciolosis in Irish dairy herds.
\end{abstract}

Keywords: fasciolosis, Fasciola hepatica, spatial cluster analysis, ELISA, Ireland.

\section{Introduction}

Fasciolosis caused by Fasciola hepatica is strongly influenced by weather conditions (Mas-Coma et al., 2009), and can account for major economic losses in cattle farms worldwide (Kaplan, 2001). The association of the free-living stages of F. hepatica, as well as the intermediate snail-host Galba truncatula, with climatic and environmental conditions indicates an important spatial element in the epidemiology of fasciolosis (Charlier et al., 2011). Therefore, the use of climatic and environmental variables can help explain the observed temporal pattern of the disease and assist the development of predictive risk models of fasciolosis (McCann et al., 2010a).

Studies, analysing the spatial distribution of fasci-

Corresponding author:

Theo de Waal

School of Veterinary Medicine, University College Dublin

UCD Veterinary Sciences Centre

Belfield, Dublin 4, Ireland

Tel. +353 1716-6178; Fax +353 1 716-6185

E-mail: theo.dewaal@ucd.ie olosis in Europe, have been performed in Belgium (Bennema et al., 2011), England and Wales (McCann et al., 2010a,b), and Germany (Kuerpick et al., 2013). The use of spatial statistics with geographical information systems (GIS) and other geospatial tools in order to detect high-risk regions can expand the current knowledge on the transmission, geographical pattern and potential risk factors of fasciolosis (Weisent et al., 2011). Spatial cluster analysis is based on such tools to identify hotspots or areas with an unusual increase in disease events grouped together in space and time (Fritz et al., 2013). There are only two studies that have used cluster detection techniques to identify highrisk regions for fasciolosis, i.e. the study by Rinaldi et al. (2009) that detected spatial clusters of fasciolosis in water buffaloes in central Italy; and the study by Bennema et al. (2011) that identified spatial clusters of fasciolosis in dairy herds in Flanders, Belgium.

Cluster analysis of fasciolosis in Ireland has not yet been used to explore patterns of distribution of the disease in dairy herds and to evaluate the spatial autocorrelation of the clusters with predictor variables. The objectives of this study were: (i) to identify local clusters of exposure to F. hepatica in selected dairy cow 
herds in Munster Province, Ireland; and (ii) to detect differences in climatic and environmental variables between the high-risk and low-risk clusters of exposure to F. hepatica.

\section{Materials and methods}

\section{Study area}

Munster is the largest province of Ireland in the South-west of the country and covers a total area of $24,675 \mathrm{~km}^{2}$ (Fig. 1). It consists of six counties (Cork, Clare, Kerry, Limerick, Tipperary and Waterford). The climate is mild and moist with higher temperatures in the coastal regions and the highest precipitation in the West. More than $60 \%$ of Irish dairy herds are located in Munster that therefore represents the main dairy farming area in Ireland (CSO, 2012).

\section{Samples}

A total of 1,292 dairy cow herds from the six counties of Munster were sampled in September 2012, each providing a single bulk tank milk (BTM) sample. They were collected from dairy farms throughout Munster in September 2012. The majority of these samples $(92 \%)$ were provided by an Irish cattle-breeding services provider that non-randomly selected all its dairy

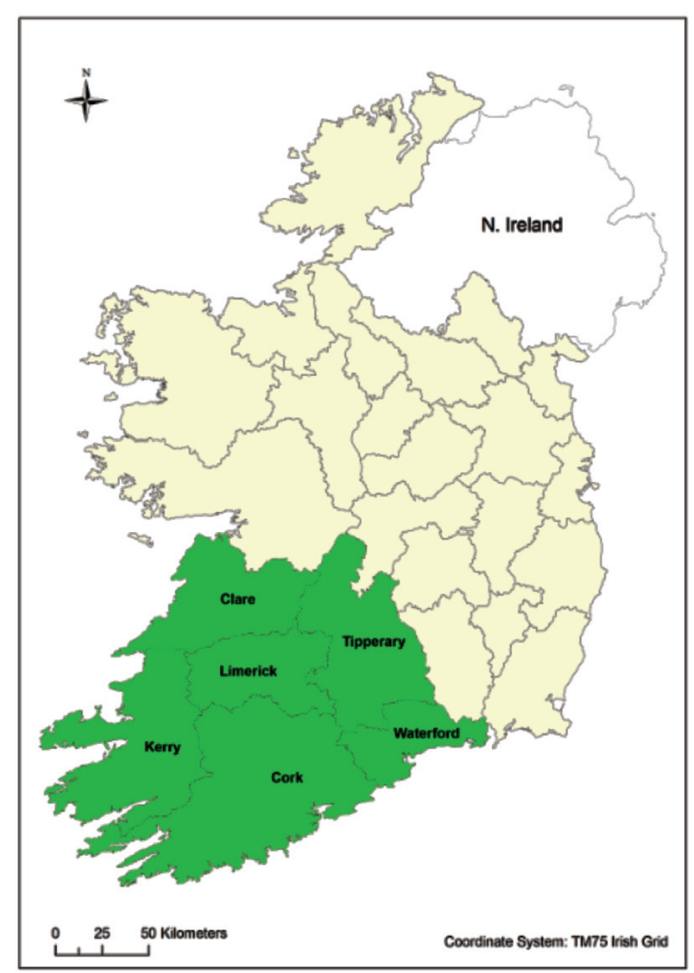

Fig. 1. The study area - Munster Province, Ireland. farmer customers in Munster. The remaining samples $(8 \%)$ were taken following discussion group meetings between advisors representing the Irish Agriculture and Food Development Authority (Teagasc) and dairy farmers in the county of Cork. All dairy farm addresses were based on their townland location. Each BTM sample was treated for preservation with a single tablet of "Broad Spectrum Microtabs II", a compound containing $0.3 \mathrm{mg}$ Natamycin and $8 \mathrm{mg}$ Bronopol (Advanced Instruments, Inc., MA, USA) and all samples were sent to the Veterinary Parasitology Laboratory of University College Dublin. After reception at the laboratory, the BTM samples were allowed to stand for a minimum 4 days at $+4{ }^{\circ} \mathrm{C}$ to allow the lipid layer to separate and be removed. The samples were then stored at $+4{ }^{\circ} \mathrm{C}$ for 8 hours prior to centrifuging for 10 minutes at $850 \mathrm{~g}$. After the removal of their lipid layer, the remaining fluid was stored in $2 \mathrm{ml}$ aliquots at $-20{ }^{\circ} \mathrm{C}$ until tested.

\section{Antibody testing}

Using an in-house antibody-detection enzyme-linked immunosorbent assay (ELISA), the levels of $F$. hepatica antibodies were determined for each BTM sample (Selemetas et al., 2014). One negative and two positive controls were used as reference standards for determining the $F$. hepatica antibody levels based on the optical density (OD) that was measured by an ELISA plate reader (Expert 96, Asys Hitech, Eugendorf, Austria) at the $450 \mathrm{~nm}$ wavelength. The antibody levels of each sample were expressed as per cent positivity (PP), according to the following equation:

$$
\mathrm{PP} \text { value }=\frac{O D \text { of test sample }}{\text { Mean OD of positive controls }} \times 100
$$

In order to define the optimal cut-off value of the ELISA test, a combination of two normal distributions for the two components (positive and negative herds) was fitted to the histogram of the PP values of the samples (Fig. 2), using the algorithm of expectation-maximization (EM) of the normal mixEM function of the Mixtools package (Benaglia et al., 2009) in the R 3.0.3 statistical language environment ( $R$ Development Core Team, 2013). The value of $\geq 15$ PP was used as cut-off, i.e. herds with a PP equal or higher than that were deemed positive, while those with PPs less than 15 were regarded as negative. Based on the mixture bimodal model, the status of the dairy herds regarding their exposure to F. hepatica was classified into positive and negative classes. 


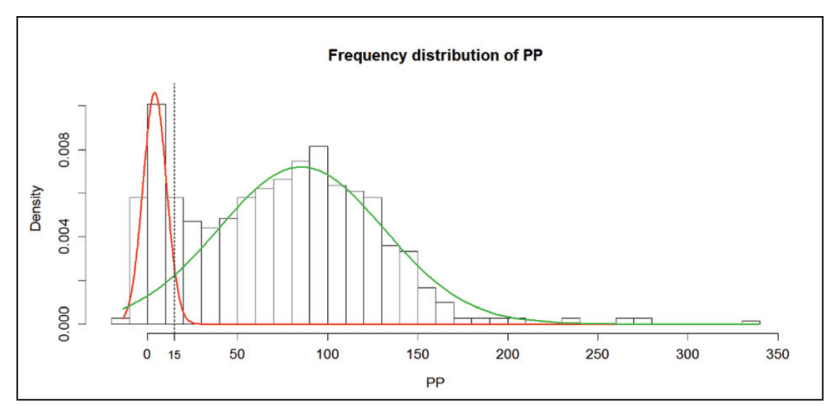

Fig. 2. Frequency distribution histogram of the per cent positivity (PP) ELISA values of milk samples and the fitted normal distributions of the two subgroups (negative and positive herds for fasciolosis).

\section{GIS mapping, georeferencing and variables}

In the present study, the GIS software that was used for the management of spatial data and the construction of spatial maps was ArcGIS version 10.1 (ESRI, Redlands, CA, USA). The dairy herds were georeferenced by using their townland location as described previously (Selemetas et al., 2015).

Several climatic and environmental variables (Table 1) were used to explain possible differences in the exposure to F. hepatica between dairy cow herds in high-risk and low-risk areas. Gridded weather data at the $1-\mathrm{km}$ resolution on the Irish Grid Reference System (TM75/Irish Grid) were obtained from the Met Éireann (the Irish National Meteorological Service) archive of observations for Ireland. The averages of monthly and seasonal mean temperatures, total rainfall $(\mathrm{mm})$ and total number of wet-days (daily rainfall $\geq 1 \mathrm{~mm}$ ) and total number of "rain-days" (daily rainfall $\geq 0.2 \mathrm{~mm}$ ) were collected and used as the climatic variables for the year 2012. We also collected the total wet-days and total rain-days, long-term averages of monthly, seasonal and annual total rainfall $(\mathrm{mm})$ and long-term averages of monthly, seasonal and annual minimum, maximum and mean temperatures for the period 1981-2010. The seasonal datasets represented the following 3-month periods: spring (March to May), summer (June to August), autumn (September to November) and winter (December to February). All climatic data sets were converted to raster files using $\mathrm{R}$ 3.0.3.

For the environmental variables, satellite values for the Normalized Difference Vegetation Index (NDVI) and the Enhanced Vegetation Index (EVI) at the spatial resolution of $250 \times 250 \mathrm{~m}$ from January to September 2012 were derived from the Moderate Resolution Imaging Spectroradiometer (MODIS) onboard the Terra satellite (http://modis.gsfc.nasa.gov/). These images were post-processed according to Scharlemann et al. (2008) by Avia-GIS (Zoersel, Belgium). Data describing various soil types (shallow and deep, welldrained, shallow and deep, poorly drained, peaty and alluvial) from the Teagasc Indicative Soils Maps for Ireland were provided by the Environmental Protection Agency (EPA) in Ireland at the $10 \times 10 \mathrm{~km}$ resolution (Daly and Fealy, 2007). Using the Zonal Statistics tool in ArcGIS, version 10.1, the values of every raster in each electoral division (the smallest legally defined administrative area in Ireland) were measured and summarised using Excel, either as the majority value for the categorical variable of soil or the mean value for the all numerical variables (climatic, NDVI, EVI).

\section{Statistical analysis}

The Getis-Ord Gi* statistic (Getis and Ord, 1992; Ord and Getis, 1995) was used to detect possible regional clusters of fasciolosis (hotspots or areas with unusually high occurrences of dairy cow herds exposed to F. hepatica) in Munster. This statistical tool is suitable for identifying the spatial reliance between an observation and adjacent observations within a defined distance threshold (Getis et al., 2003). The cluster analysis was performed using the Getis-Ord Gi* Hot Spot Analysis tool in ArcGIS, using the sampled electoral divisions as spatial map units. A sampled electoral division was defined as exposed to F. hepatica if the majority of sampled herds in the area of the electoral division had been exposed to the parasite, otherwise it was defined as non-exposed.

The statistical tool used is distance-based and the fixed distance method was utilized for the conceptualization of spatial relationships, as there was a large variation in electoral division sizes. According to this method adjacent features within a specified distance get a weight of 1 on their impact when calculating the target feature; adjacent features outside the specified distance have zero weight in this repect. The critical distance was set to 23 $\mathrm{km}$ based on the size of electoral divisions and the peak value of the Moran's I Z Score (Anselin, 1995), which reflects maximum spatial autocorrelation calculated for multiple distances using the Spatial Autocorrelation Tool. The Gi* values of the test represent a standard normal variant with its associated probability derived from the z-score distribution (Getis et al., 2003). Only Gi* values greater than 2.58 and less than -2.58 (representing $\mathrm{P} \leq 0.01)$ were used to indicate high-risk clusters (areas with unusually high occurrences of dairy herds exposed to F. hepatica) and low-risk clusters (areas with 
Table 1. Properties, data sources and resolution of the climatic and environmental variables used in the current study.

\begin{tabular}{|c|c|c|c|}
\hline Variable $^{1}$ & Period & Source & Spatial resolution \\
\hline Annual mean temperature & 2012 & Met Éireann & $1 \times 1 \mathrm{~km}$ \\
\hline Mean 2012 January-September temperature & January-September 2012 & Met Éireann & $1 \times 1 \mathrm{~km}$ \\
\hline Mean winter temperature & December 2011-February 2012 & Met Éireann & 1 x $1 \mathrm{~km}$ \\
\hline Mean spring temperature & March-May 2012 & Met Éireann & $1 \times 1 \mathrm{~km}$ \\
\hline Mean summer temperature & June-August 2012 & Met Éireann & $1 \times 1 \mathrm{~km}$ \\
\hline Avg. annual mean temperature & $1981-2010$ & Met Éireann & $1 \times 1 \mathrm{~km}$ \\
\hline Mean January-December temperature & $1981-2010$ & Met Éireann & $1 \times 1 \mathrm{~km}$ \\
\hline Mean winter temperature & December-February 1981-2010 & Met Éireann & $1 \mathrm{x} 1 \mathrm{~km}$ \\
\hline Mean spring temperature & March-May 1981-2010 & Met Éireann & $1 \times 1 \mathrm{~km}$ \\
\hline Mean summer temperature & June-August 1981-2010 & Met Éireann & $1 \times 1 \mathrm{~km}$ \\
\hline Mean autumn temperature & September-November 1981-2010 & Met Éireann & $1 \times 1 \mathrm{~km}$ \\
\hline Avg. maximum temperature & $1981-2010$ & Met Éireann & $1 \times 1 \mathrm{~km}$ \\
\hline Avg. January-December maximum temperature & January-December 1981-2010 & Met Éireann & $1 \times 1 \mathrm{~km}$ \\
\hline Avg. winter maximum temperature & December-February 1981-2010 & Met Éireann & $1 \times 1 \mathrm{~km}$ \\
\hline Avg. annual mean rainfall & March-May 1981-2010 & Met Éireann & $1 \times 1 \mathrm{~km}$ \\
\hline Avg. summer maximum temperature & June-August 1981-2010 & Met Éireann & $1 \times 1 \mathrm{~km}$ \\
\hline Avg. autumn maximum temperature & September-November 1981-2010 & Met Éireann & $1 \times 1 \mathrm{~km}$ \\
\hline Avg. minimum temperature & $1981-2010$ & Met Éireann & $1 \times 1 \mathrm{~km}$ \\
\hline Avg. January-December minimum temperature & January-December 1981-2010 & Met Éireann & $1 \times 1 \mathrm{~km}$ \\
\hline Avg. winter minimum temperature & December-February 1981-2010 & Met Éireann & $1 \times 1 \mathrm{~km}$ \\
\hline Avg. spring minimum temperature & March-May 1981-2010 & Met Éireann & $1 \times 1 \mathrm{~km}$ \\
\hline Avg. summer minimum temperature & June-August 1981-2010 & Met Éireann & $1 \times 1 \mathrm{~km}$ \\
\hline Avg. autumn minimum temperature & September-November 1981-2010 & Met Éireann & $1 \times 1 \mathrm{~km}$ \\
\hline Avg. annual mean rainfall & 2012 & Met Éireann & $1 \times 1 \mathrm{~km}$ \\
\hline Mean January-September rainfall & January-September 2012 & Met Éireann & $1 \times 1 \mathrm{~km}$ \\
\hline Mean winter rainfall & December 2011-February 2012 & Met Éireann & $1 \times 1 \mathrm{~km}$ \\
\hline Mean spring rainfall & March-May 2012 & Met Éireann & $1 \times 1 \mathrm{~km}$ \\
\hline Mean summer rainfall & June-August 2012 & Met Éireann & $1 \times 1 \mathrm{~km}$ \\
\hline Total rain-days & 2012 & Met Éireann & $1 \times 1 \mathrm{~km}$ \\
\hline Total wet-days & 2012 & Met Éireann & $1 \times 1 \mathrm{~km}$ \\
\hline Annual mean rainfall & $1981-2010$ & Met Éireann & $1 \times 1 \mathrm{~km}$ \\
\hline Mean January-December rainfall & January-December 1981-2010 & Met Éireann & $1 \times 1 \mathrm{~km}$ \\
\hline Mean winter rainfall & December-February 1981-2010 & Met Éireann & $1 \times 1 \mathrm{~km}$ \\
\hline Mean spring rainfall & March-May 1981-2010 & Met Éireann & $1 \times 1 \mathrm{~km}$ \\
\hline Mean summer rainfall & June-August 1981-2010 & Met Éireann & $1 \times 1 \mathrm{~km}$ \\
\hline Mean autumn rainfall & September-November 1981-2010 & Met Éireann & $1 \times 1 \mathrm{~km}$ \\
\hline Avg. total rain-days & $1981-2010$ & Met Éireann & $1 \times 1 \mathrm{~km}$ \\
\hline Avg. total wet-days & $1981-2010$ & Met Éireann & $1 \times 1 \mathrm{~km}$ \\
\hline NDVI for January-September & January-September 2012 & Avia-GIS², MODIS 3 & $250 \times 250 \mathrm{~m}$ \\
\hline EVI for January-September & January-September 2012 & Avia-GIS², MODIS 3 & $250 \times 250 \mathrm{~m}$ \\
\hline Soil GIS data & 2006 & Teagasc $^{4}, \mathrm{FS}^{5}, \mathrm{EPA}^{6}, \mathrm{GSI}^{7}$ & $10 \times 10 \mathrm{~km}$ \\
\hline
\end{tabular}

${ }^{1}$ Temperatures in ${ }^{\circ} \mathrm{C}$, rainfall in $\mathrm{mm} ;{ }^{2}$ Agriculture and veterinary information and analysis, a Belgian small/medium enterprise (SME); ${ }^{3}$ Moderate resolution imaging spectroradiometer; ${ }^{4}$ Irish agriculture and food development authority; ${ }^{5}$ Forest service; ${ }^{6}$ Environmental protection agency, Ireland; ${ }^{7}$ Geological survey, Ireland.

unusually high occurrences of dairy cow herds notexposed to F. hepatica), respectively.

Descriptive statistics, 95\% confidence intervals (CI) and all statistical tests were performed using SPSS Statistics, version 20.0 (IBM Corp, NY, USA). The relationships between climatic and environmental variables with statistically significant high-risk and low-risk clusters of exposure to F. hepatica were deter- mined at the electoral division level. These significant differences in climatic and environmental variables between high- and low-risk spatial clusters of F. hepatica exposure were identified using a pair-wise MannWhitney $U$ test for numerical variables (Sokal and Rohlf, 1995) and the Pearson's chi-square test (Rao and Scott, 1987) for the categorical soil variable. The significance was set at $\mathrm{P}<0.05$. 


\section{Results}

The normal distributions of the two-component model (positive and negative herds) and the histogram of the frequency distribution of PP values of BTM samples produced with $\mathrm{R}$ 3.0.3 are shown in Fig. 2. The distribution of herds for which BTM samples were submitted is illustrated in Fig. 3. The analysis of the 1,292 BTM samples showed that $65 \%$ ( $\mathrm{n}=842)$ of the dairy herds had been exposed to F. hepatica. The distribution of BTM samples per county and the prevalence of fasciolosis for each county is shown in Table 2. The distribution of sampled electoral divisions that were subsequently classified as exposed or non-exposed is shown in Fig. 4.

\section{Cluster analysis}

A total number of 16 statistically significant highrisk clusters of fasciolosis were found across Munster (Fig. 5). These clusters were located in western Kerry $(\mathrm{n}=4)$, central Clare $(\mathrm{n}=2)$, western and eastern Limerick $(n=4)$ and north-western Cork $(n=6)$. In addition, 24 statistically significant low-risk clusters were found in south Tipperary $(\mathrm{n}=11)$, eastern Waterford $(\mathrm{n}=1)$ and south-eastern Cork $(n=12)$. The spatial distribution of high-risk clusters appeared more dispersed and mainly located in the northern and western regions of Munster compared to the low-risk clusters that were mostly concentrated in the southern and eastern regions (Fig. 5).

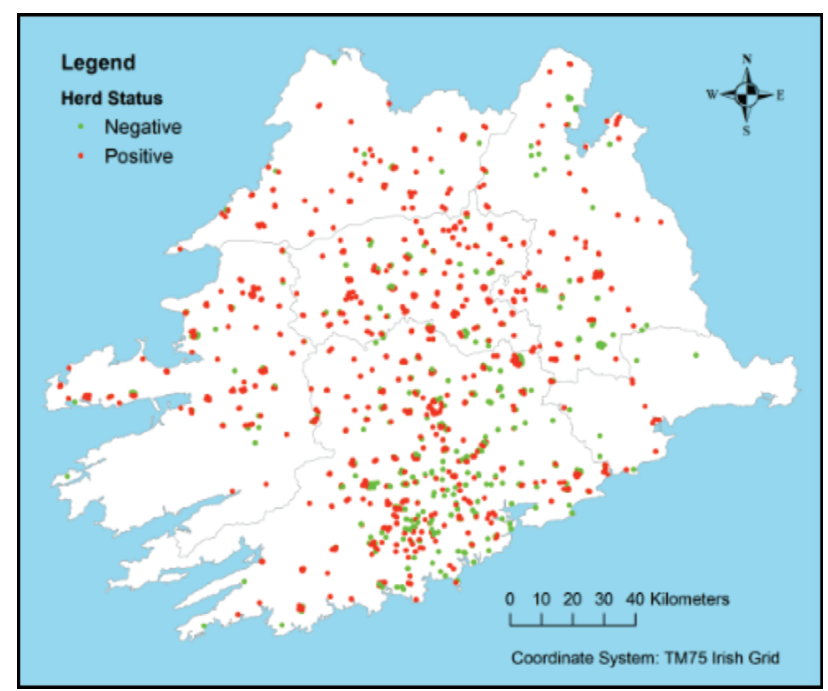

Fig. 3. Location of the sampled dairy herds $(n=1,292)$ and the distribution of negative and positive herds for fasciolosis in Munster Province, Ireland.
Table 2. Distribution of sampled herds (negative and positive) per county in Munster Province based on F. hepatica antibody levels of each herd expressed as per cent positivity (PP) and the associated prevalence of fasciolosis.

\begin{tabular}{lcccc}
\hline County & $\begin{array}{c}\text { Herds } \\
(\mathrm{n})\end{array}$ & $\begin{array}{c}\text { Negative } \\
(\mathrm{PP}<15)\end{array}$ & $\begin{array}{c}\text { Positive } \\
(\mathrm{PP}>15)\end{array}$ & $\begin{array}{c}\text { Prevalence } \\
(\%)\end{array}$ \\
\hline Clare & 89 & 14 & 75 & 84 \\
Kerry & 129 & 27 & 102 & 79 \\
Limerick & 228 & 55 & 173 & 76 \\
Tipperary & 141 & 50 & 91 & 65 \\
Waterford & 15 & 6 & 9 & 60 \\
Cork & 690 & 298 & 392 & 57 \\
Total & 1292 & 450 & 842 & 65 \\
\hline
\end{tabular}

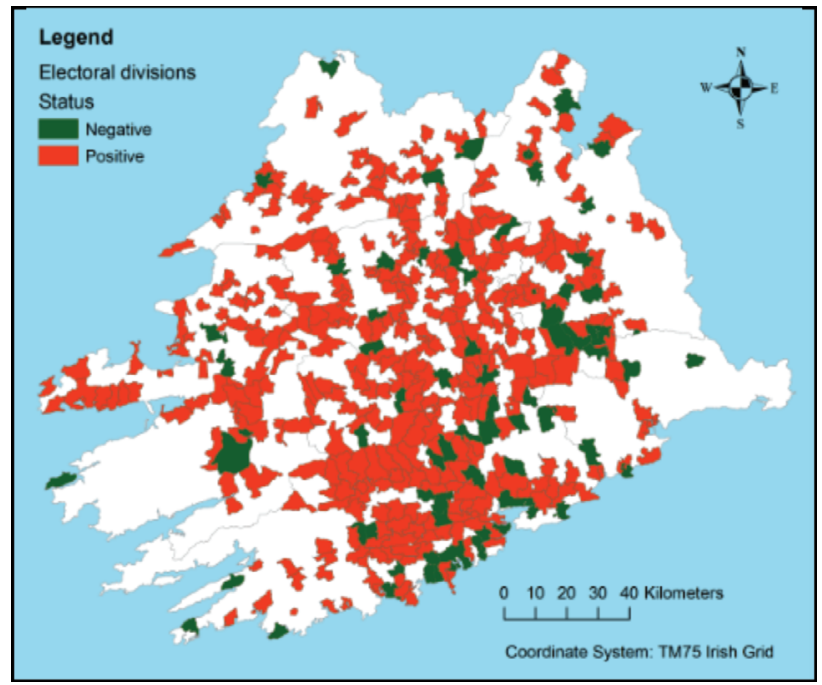

Fig. 4. Distribution of sampled electoral divisions found to be exposed and non-exposed to F. hepatica in Munster Province. A sampled electoral division was defined as exposed if the majority of sampled herds within the electoral division had been exposed to $F$. hepatica, otherwise it was defined as non-exposed.

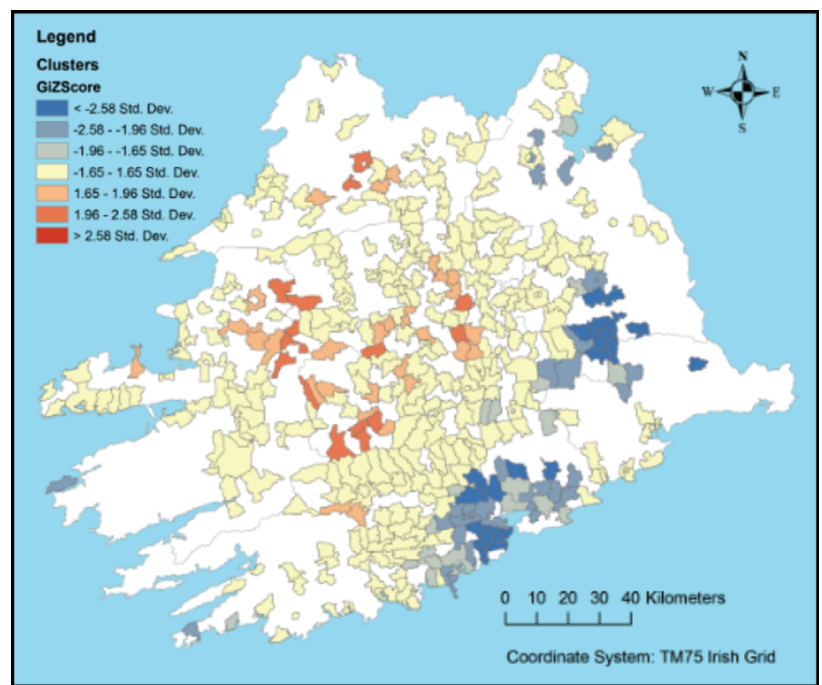

Fig. 5. Statistically significant $(\mathrm{P}<0.01)$ high-risk $(\mathrm{n}=16)$ and low-risk $(n=24)$ clusters of fasciolosis in Munster Province, based on the Getis-Ord Gi* statistic z-scores. 


\section{Climatic and environmental variables}

Thirteen high-risk clusters were exposed to $F$. hepatica, while 22 low-risk clusters were not. Table 3 shows the Mann-Whitney U test results of pair-wise comparison between the 20 most statistically significant climatic and environmental variables vis-à-vis the lowrisk and high-risk clusters. There was a significant difference $(\mathrm{P}<0.001)$ between the rank sums of the clusters with the long-term averaged total number of wetdays and rain-days and the contemporary values of these variables. Indeed, these were regarded the most significant variables of the test. The differences related to rainfall constituted the second most significant category $(\mathrm{P}<0.001)$. Regarding the NDVI variables only the monthly values in September and August were significant at the level of $\mathrm{P}<0.001$ with the former being the more significant, whereas all the other NDVI variables were not significant $(\mathrm{P}>0.05)$. Finally, there was no significant difference $(\mathrm{P}>0.05)$ between the rank sums of the clusters with the EVI variables.

The differences in exposure to F. hepatica of the two classes of clusters were shown to be strongly dependent on the types of soil $\left(\chi^{2}=8.87, \mathrm{df}=2, \mathrm{P}<0.01\right)$ based on the Pearson's chi-square test. Well drained soils had a bigger proportion among the low-risk clusters, whereas poorly drained soils presented a higher proportion among the high-risk clusters.

\section{Discussion}

The rationale of this study was to detect differences in climatic and environmental variables between the hotspots and coldspots of exposure to F. hepatica identified by cluster analysis. The aim was to investigate the heterogeneous spatial distribution patterns of fasciolosis to find underlying reasons that could suggest environmental threats and potential risk factors explaining the observed regional differences (Ramis et al., 2014). The selection of Munster as study area was ideal, because it is the most important dairy farming area in Ireland and is characterised by considerable regional differences in weather conditions in its territory.

The present study determined the exposure to F. hepatica of 1,292 dairy cow herds in six Munster counties in September 2012 and constitutes the first attempt to identify clusters of fasciolosis in this area and link them to significant climatic and environmental predictors for F. hepatica exposure risk. The preva-

Table 3. Summary of the Mann-Whitney U test statistics comparing high-risk versus low-risk spatial fasciolosis clusters in Munster Province with the 20 most statistically significant $(\mathrm{P}<0.01)$ climatic and environmental variables.

\begin{tabular}{|c|c|c|c|c|c|c|c|}
\hline \multirow{2}{*}{ Variable* } & \multicolumn{3}{|c|}{ Mean } & \multicolumn{2}{|c|}{$95 \%$ Confidence Interval } & \multirow{2}{*}{ Z score } & \multirow{2}{*}{$\mathrm{P}$} \\
\hline & $\begin{array}{l}\text { Munster } \\
\text { Province }\end{array}$ & High-risk & Low-risk & High-risk & Low-risk & & \\
\hline Total wet-days 2012 (n) & 204.41 & 227.10 & 181.31 & $221.20-232.99$ & $172.81-189.81$ & -4.55 & $<0.0001$ \\
\hline Avg. total rain-days 1981-2010 (n) & 248.71 & 265.09 & 233.78 & 260.11-270.07 & $227.66-239.90$ & -4.34 & $<0.0001$ \\
\hline Avg. total wet-days 1981-2010 (n) & 183.34 & 201.01 & 168.09 & $193.16-208.87$ & $161.65-174.52$ & -4.31 & $<0.0001$ \\
\hline Rainfall September 2012 & 51.56 & 74.22 & 32.12 & $61.58-86.87$ & $24.59-39.65$ & -4.24 & $<0.0001$ \\
\hline Rainfall April 2012 & 103.16 & 129.99 & 86.96 & $112.52-147.45$ & $80.87-93.05$ & -4.13 & $<0.0001$ \\
\hline Rainfall January 2012 & 110.99 & 146.74 & 84.90 & $124.68-168.79$ & 72.78-97.02 & -4.09 & $<0.0001$ \\
\hline Total rain-days 2012 (n) & 274.22 & 290.01 & 254.74 & $285.45-294.57$ & $245.70-263.77$ & -3.95 & $<0.0001$ \\
\hline Rainfall March 2012 & 29.02 & 34.13 & 24.76 & 31.27-36.99 & 21.81-27.72 & -3.85 & $<0.0001$ \\
\hline NDVI for September & 0.72 & 0.78 & 0.71 & $0.76-0.80$ & $0.68-0.73$ & -3.56 & 0.0002 \\
\hline NDVI for August & 0.73 & 0.78 & 0.72 & $0.76-0.80$ & $0.69-0.74$ & -3.35 & 0.0005 \\
\hline Rainfall January 1981-2010 & 133.45 & 149.83 & 121.043 & $129.02-170.65$ & $113.59-128.50$ & -3.03 & 0.002 \\
\hline Rainfall winter 1981-2010 & 362.38 & 407.75 & 325.71 & $351.08-464.43$ & $304.59-346.82$ & -3.00 & 0.002 \\
\hline Avg. min. temp. August 1981-2010 & 19.28 & 19.00 & 19.44 & 18.74-19.25 & 19.17-19.71 & -2.94 & 0.002 \\
\hline Rainfall February 2012 & 45.78 & 52.65 & 36.26 & $43.98-61.33$ & $30.95-41.58$ & -2.92 & 0.003 \\
\hline Avg. temp. July 1981-2010 & 15.41 & 15.09 & 15.60 & $14.80-15.39$ & $15.45-15.75$ & -2.89 & 0.003 \\
\hline Rainfall February 1981-2010 & 98.48 & 110.55 & 88.06 & $94.69-126.41$ & $82.36-93.76$ & -2.82 & 0.004 \\
\hline Avg. min. temp. June 1981-2010 & 9.53 & 9.16 & 9.78 & $8.84-9.48$ & $9.51-10.05$ & -2.84 & 0.004 \\
\hline Avg. temp. August 1981-2010 & 15.25 & 14.95 & 15.42 & $14.66-15.24$ & $15.28-15.55$ & -2.78 & 0.004 \\
\hline Avg. temp. September 1981-2010 & 13.31 & 13.01 & 13.46 & $12.74-13.28$ & $13.29-13.63$ & -2.73 & 0.005 \\
\hline Avg. annual temp. 1981-2010 & 9.93 & 9.62 & 10.08 & $9.35-9.89$ & $9.89-10.28$ & -2.75 & 0.005 \\
\hline
\end{tabular}

*Temperatures in ${ }^{\circ} \mathrm{C}$, rainfall in $\mathrm{mm}$ 
lence of the exposed dairy herds $(65 \%)$ confirms the relatively high exposure to F. hepatica among dairy herds in Munster. It represents the first study attempting cluster analysis to develop a predictive risk model for fasciolosis in Ireland. Outbreak predictions with respect to fasciolois in this country are presently based on the Ollerenshaw index that uses the number of rain-days, evapotranspiration and monthly rainfall levels (de Waal et al., 2007). However, the current study identified a model with the ability to forecast these outbreaks on a much smaller regional scale and with greater precision. The results highlight the importance of cluster analysis for identifying regional hotspots of fasciolosis and significant climatic and environmental risk factors, which can improve the knowledge on the epidemiology of the disease and the accuracy of a predictive model for fasciolosis in Ireland.

The results of the current study are similar to the F. hepatica prevalence $(65 \%)$ in culled cows during autumn and summer in Ireland (Murphy et al., 2006) and the prevalence $(75 \%)$ among Irish dairy herds in November (Bloemhoff et al., 2012). The high prevalence observed in Irish dairy herds can be attributed to the combination of high level of grass-based diet and temperate climate during grazing period that can increase the exposure to parasites (O'Farrell et al., 1986). Indeed, the main features of Irish dairy farming are the temperate climate supporting a low-input, pasture-based production system, a high proportion of spring-calving cows and a long grazing season that allows dairy cattle to graze outdoors from early spring to late autumn (Creighton et al., 2011; Läpple et al., 2012). The cluster analysis identified 16 statistically significant high-risk clusters mostly located in northern and western regions of Munster and 24 statistically significant low-risk clusters, mainly in the southern and eastern regions (Fig. 5). These findings are in accordance with the study by Selemetas et al. (2015) who found, using a Random Forest regression model, a higher proportion of areas where dairy herds had been exposed to F. hepatica in the western part of Ireland.

The most significant classes of variables that could reflect the difference between the two different categories of clusters were the total number of wet-days and rain-days, rainfall, NDVI, temperature and soil types. These findings highlight the role of precipitation, grazing and drainage on the survival and development of parasitic stages of F. hepatica and the intermediate snail hosts. Differences in the climatic and environmental variables for high-risk and low-risk clusters were consistent with the findings of research studies, which suggested (using different approaches) that the total number of wet days (McCann et al., 2010a; Selemetas et al., 2015), rain-days (Selemetas et al., 2015), amount of rainfall (Malone et al., 1998; Yilma and Malone, 1998; McCann et al., 2010a,b; Bennema et al., 2011; Martins et al., 2012), NDVI (Fuentes, 2004, 2006; Durr et al., 2005; Fuentes et al., 2005), temperature (Malone et al., 1998; Yilma and Malone, 1998; Bossaert et al., 1999; McCann et al., 2010a,b; Martins et al., 2012) and soil type (McCann et al., 2010a) may play a role in the exposure to F. hepatica. In addition, the association of well drained soils with low-risk clusters with poorly drained soils with high-risk clusters reflects the importance of impeded drainage for the transmission of fasciolosis, which is in agreement with the findings reported by Charlier et al. (2011). Finally, the results in this study are in contrast to the weak correlation of rainfall and temperature with the seroprevalence of fasciolosis in Germany (Kuerpick et al., 2013), possibly due to low level of spatial variation of these variables in the country.

Although the BTM samples were not randomly collected and the sampling did not cover the whole area of Munster, the number of submitted BTM samples $(\mathrm{n}=1,292)$ was sufficient to provide a satisfactory coverage of Munster as well as power for the cluster analysis. Additionally, it is likely that the present study did not examine all the potential risk factors of the exposure to fasciolosis, since positive and negative herds may co-exist close to each other within low or high-risk areas depending on specific farm management practices and availability of suitable habitats for the snail-host (Bennema et al., 2009). For these reasons, the logistic regression model proposed by Bennema et al. (2011) for Flanders in Belgium, which included management, environmental and climatic factors, outperformed in accuracy their second regression model that was based only on environmental and climatic factors.

The use of BTM samples for detecting exposure to F. hepatica is a popular, quick and easy diagnostic method, but it must be remembered that ELISA results based on a single BTM sample depend on the in-herd prevalence and seropositivity of the lactating cows contributing to the BTM sample (Duscher et al., 2011). An additional limitation is that the positive result of an antibody-detection test rather reveals the history of exposure than an existing infection (SalimiBejestani et al., 2005). Finally, the collection of BTM samples for this study in September may not fully esti- 
mate the exposure to F. hepatica, as the expected peak of annual exposure to the disease usually occurs in late autumn (Salimi-Bejestani et al., 2005).

\section{Acknowledgements}

The authors gratefully acknowledge the assistance and cooperation of Teagasc advisors, Munster Cattle Breeding Group and farmers in providing samples for this study. We also thank Met Éireann and Seamus Walsh for supplying weather data and Avia-GIS for providing MODIS Terra data. Soils data generated by Teagasc with co-operation of the Forest Service, EPA and GSI. Project completed May 2006. Maps of Munster province, Ireland and electoral divisions were sourced from Urban Institute of Ireland. The research leading to these results received funding from the European Community's Seventh Framework Programme (FP7/2007-2013) under grant agreement no 288975 (GLOWORM).

\section{References}

Anselin L, 1995. Local indicators of spatial association-LISA. Geogr Anal 2, 93-115.

Benaglia T, Chauveau D, Hunter DR, Young D, 2009. Mixtools: an $\mathrm{R}$ package for analyzing finite mixture models. J Stat Softw 32, 1-29.

Bennema S, Vercruysse J, Claerebout E, Schnieder T, Strube C, Ducheyne E, Hendrickx G, Charlier J, 2009. The use of bulktank milk ELISAs to assess the spatial distribution of Fasciola hepatica, Ostertagia ostertagi and Dictyocaulus viviparus in dairy cattle in Flanders (Belgium). Vet Parasitol 165, 51-57.

Bennema SC, Ducheyne E, Vercruysse J, Hendrickx G, Claerebout E, Charlier J, 2011. Relative importance of management, meteorological and environmental factors in the spatial distribution of Fasciola hepatica in dairy cattle in a temperate climate zone. Int J Parasitol 41, 225-233.

Bloemhoff Y, Sayers R, Byrne N, Good B, 2012. Liver fluke in Irish dairy herds. Teagasc Res 7, 32-33.

Bossaert K, Lonneux JF, Losson B, Peeters J, 1999. Fasciolosis incidence forecasts in Belgium by means of climatic data. Ann Med Vet 143, 201-211.

Charlier J, Bennema SC, Caron Y, Counotte M, Ducheyne E, Hendrickx G, Vercruysse J, 2011. Towards assessing fine-scale indicators for the spatial transmission risk of Fasciola hepatica in cattle. Geospat Health 5, 239-245.

Creighton P, Kennedy E, Boland T, Shalloo L, O’Donovan M, 2011. A survey analysis of grassland dairy farming in Ireland, investigating grassland management, technology adoption and sward renewal. Grass Forage Sci 66, 251-264.

CSO (Central Statistics Office) Ireland, 2012. Census of Agriculture 2010 - Final results. Stationary Office, Dublin, Ireland, $129 \mathrm{pp}$.
Daly K, Fealy R, 2007. Digital soil information system for Ireland. Scoping Study (2005-S-DS-22-M1). Final Report. Environmental Protection Agency, Wexford, Ireland.

de Waal T, Relf V, Good B, Gray J, Murphy T, Forbes A, Mulcahy G, 2007. Developing models for the prediction of Fasciolosis in Ireland. In: Making science work on the farm: a workshop on decision support systems for Irish agriculture. Holden NM, Hochstrasser T, Schulte RPO, Walsh S (eds). Dublin: Agmet, 60-63 pp.

Durr PA, Tait N, Lawson AB, 2005. Bayesian hierarchical modelling to enhance the epidemiological value of abattoir surveys for bovine fasciolosis. Prev Vet Med 71, 157-172.

Duscher R, Duscher G, Hofer J, Tichy A, Prosl H, Joachim A, 2011. Fasciola hepatica - Monitoring the milky way? The use of tank milk for liver fluke monitoring in dairy herds as base for treatment strategies. Vet Parasitol 178, 273-278.

Fritz CE, Schuurman N, Robertson C, Lear S, 2013. A scoping review of spatial cluster analysis techniques for point-event data. Geospat Health 7, 183-198.

Fuentes MV, 2004. Proposal of a geographic information system for modelling zoonotic fasciolosis transmission in the Andes. Parasitol Latinoam 59, 51-55.

Fuentes MV, 2006. Remote sensing and climate data as a key for understanding fasciolosis transmission in the Andes: a review and update of an ongoing interdisciplinary project. Geospat Health 1, 59-70.

Fuentes MV, Sainz-Elipe S, Nieto P, Malone JB, Mas-Coma S, 2005. Geographical information systems risk assessment models for zoonotic fasciolosis in the South American Andes region. Parassitologia 47, 151-156.

Getis A, Morrison AC, Gray K, Scott TW, 2003. Characteristics of the spatial pattern of the dengue vector, Aedes aegypti, in Iquitos, Peru. Am J Trop Med Hyg 69, 494-505.

Getis A, Ord JK, 1992. The analysis of spatial association by use of distance statistics. Geogr Anal 24, 189-206.

Kaplan RM, 2001. Fasciola hepatica: a review of the economic impact in cattle and considerations for control. Vet Ther 2, 4050.

Kuerpick B, Conraths FJ, Staubach C, Fröhlich A, Schnieder T, Strube C, 2013. Seroprevalence and GIS-supported risk factor analysis of Fasciola hepatica infections in dairy herds in Germany. Parasitology 140, 1051-1060.

Läpple D, Hennessy T, O’Donovan M, 2012. Extended grazing: a detailed analysis of Irish dairy farms. J Dairy Sci 95, 188195.

Malone JB, Gommes R, Hansen J, Yilma JM, Slingenberg J, Snijders F, Nachtergaele F, Ataman E. 1998. A geographic information system on the potential distribution and abundance of Fasciola hepatica and F. gigantica in east Africa based on Food and Agriculture Organization databases. Vet Parasitol 78, 87-101.

Martins IVF, de Avelar BR, Pereira MJ, da Fonseca AH, 2012. 
Application of a geographical information system approach for risk analysis of fascioliasis in southern Espirito Santo state, Brazil. Geospat Health 6, 87-93.

Mas-Coma S, Valero MA, Bargues MD, 2009. Climate change effects on trematodiases, with emphasis on zoonotic fascioliasis and schistosomiasis. Vet Parasitol 163, 264-280.

McCann CM, Baylis M, Williams DJL, 2010a. The development of linear regression models using environmental variables to explain the spatial distribution of Fasciola hepatica infection in dairy herds in England and Wales. Int J Parasitol 40, 1021 1028.

McCann CM, Baylis M, Williams DJL, 2010b. The seroprevalence and spatial distribution of Fasciola hepatica infected dairy herds in England and Wales. Vet Rec 166, 612-617.

Murphy TM, Fahy KN, McAuliffe A, Forbes AB, Clegg TA, O'Brien DJ, 2006. A study of helminth parasites in culled cows from Ireland. Prev Vet Med 76, 1-10.

O'Farrell KJ, Downey NE, Sherington J, 1986. The effect of anthelmintic treatment at calving on the subsequent milk production characteristics of dairy cows. Irish Vet J 40, 116-123.

Ord JK, Getis A, 1995. Local spatial autocorrelation statistics: distributional issues and an application. Geogr Anal 27, 286-306.

Ramis R, Gomez-Barroso D, López-Abente G, 2014. Cluster detection of diseases in heterogeneous populations: an alternative to scan methods. Geospat Health 8, 517-526.

Rao JNK, Scott AJ, 1987. On simple adjustments to chi-square tests with sample survey data. Ann Stat 15, 385-397.

R Development Core Team, 2013. R: a language and environment for statistical computing. Vienna: R Foundation for Statistical Computing.
Rinaldi L, Musella V, Veneziano V, Condoleo RU, Cringoli G, 2009. Helmintic infections in water buffaloes on Italian farms: a spatial analysis. Geospat Health 3, 233-239.

Salimi-Bejestani MR, McGarry JV, Felstead S, Ortiz P, Akca A, Williams DJL, 2005. Development of an antibody-detection ELISA for Fasciola hepatica and its evaluation against a commercially available test. Res Vet Sci 78, 177-181.

Scharlemann JPW, Benz D, Hay SI, Purse BV, Tatem AJ, 2008. Global data for ecology and epidemiology: a novel algorithm for temporal fourier processing MODIS data. PLoS One 3, e1408.

Selemetas N, Ducheyne E, Phelan P, O’ Kiely P, Hendrickx G, de Waal T, 2015. Spatial analysis and risk mapping of Fasciola hepatica infection in dairy herds in Ireland, using random regression Forest modelling and geographical information systems. Geospat Health 9, 281-291.

Selemetas N, Phelan P, O’ Kiely P, de Waal T, 2014. Weather and soil type affect incidence of Fasciolosis in dairy cow herds. Vet Rec 175, 371.

Sokal R, Rohlf F, 1995. Biometry (third edition). Freman WH and Company, New York, 937 pp.

Torgerson P, Claxton JR, 1999. Epidemiology and control. In: Fasciolosis. Dalton JP (ed). CABI Publishing, Oxon and New York, 113-149 pp.

Weisent J, Rohrbach B, Dunn JR, Odoi A, 2011. Detection of high risk campylobacteriosis clusters at three geographic levels. Geospat Health 5, 239-245.

Yilma JM, Malone JB, 1998. A geographic information system forecast model for strategic control of fasciolosis in Ethiopia. Vet Parasitol 78, 103-127. 